\title{
The Effectiveness of an Educational-Learning Program Based on the Theory of Cognitive Load in the Achievement of Students in the General Psychology Subject in Colleges of Education and in the Development of their Future Thinking
}

\author{
Suaad Najem Abdullah, Prof. Dr. Naz Badrkhan Abdullah \\ g11408@uowasit.edu.iq,naz@ircoedu.uobaghdad.edu.iq \\ Baghdad University/ College of Education for Humanities/ Ibn Rushed
}

\begin{abstract}
This educational-learning program is based on the theory of the cognitive load in achieving general psychology for students of colleges of education and developing their future thinking. The two researchers relied on an experimental design with partial control. The design of these two equal groups involves a pre- and post-test for future thinking and a post-achievement test. Group (B) is the experimental group that studies the subject of general psychology according with the program. This group consists of (65) male and female students while group (A) is the control group that studies the same subject according to the traditional method, (65) students. The two researchers statistically equalized both groups in a number of variables to be measured by the researcher-made tools. The first tool was an achievement test of (40) items with (30) objective items and (10) essay items. The validity and consistency were verified, distinguishing its items, their level of difficulty, and the effectiveness of the wrong alternatives. The researchers also prepared a correction standard. The second tool measures the future thinking in its final form of (40) items, with a five-point scale with a discretionary scale (always, often, sometimes, rarely, never). There is a statistically significant difference between the students of the two research groups in the achievement test and future thinking, in favor of the experimental group. This means that the educational-learning program had a positive effect on students' achievement. Thus, the null hypothesis is rejected. Based on the results, conclusions, recommendations and proposals are set.
\end{abstract}

Keywords:

Teaching program, tutorial, burden theory, development of thinking.

Article Received: 18 October 2020, Revised: 3 November 2020, Accepted: 24 December 2020

\section{Part One}

\section{Introduction}

The two researchers believe that educational learning programs are one of the main elements necessary for the educational process, which helps in achieving the quality of education on the one hand, and meets the needs of society on the other hand. This reflects the educational programs in the educational stages, the state of society, and the extent of progress made at the level of the age. Also, it is necessary for Educational programs to keep pace with the progress made in information and communication technology. In addition, they must be constantly updated and developed to help achieve the quality of education on the one hand, and to meet the needs of society on the other hand. To attract the learners' attention, raise their motivation, and appropriate direction for the learners' activity and move away from randomness. The practical side has been employed by training the learners to solve real and realistic problems that require the higher thinking and develop solutions. The theoretical and practical importance of the current study is evident in the following:

\section{Problem of the Study}

The teaching methods commonly used in the educational field greatly involve a great amount of memorization and rote memorization. They hardly focus on the students' cognitive methods in dealing with academic information. This is reflected in the academic performance. In addition, there is an apparent lack in the achievement in general psychology in particular, which made the focus on the cognitive methods of students in dealing with academic information. After the education process focused on the 
regulation of the stimuli of the external educational environment, the interest in creating educational learning situations appeared (AlZaghoul, 2012) and is confirmed (Al-Ahbani, 2017). It attributed the shortcoming and decline to the use of common traditional teaching methods due to the preference of teaching general psychology of these methods. This is because their ease of use and their weak experience with modern teaching methods etc. Accordingly, the problem of the current research appears in the following question (is the educational-learning program according to the theory cognitive load effective in obtaining general psychology for students of the Faculties of Education and developing their future thinking? ).

\section{Theoretical importance:}

1. It is important in the educational learning programs planned and organized according to real rules and foundations that take into account the interests and attitudes of learners to enhance their selfconfidence. They, thus, raise the quality of education and achieving the required goals.

2. It is important in the cognitive load theory in reducing the mental quantity associated with the learning process, which allows active learning for the learner.

3. The university stage is the basis for building and developing the future. Through the outputs and outcomes of education, a conscious and trained group emerge who are able to solve problems and has the ability to employ learning in various aspects of life.

4. Academic achievement is the backbone of the success of the educational institution and makes students able to produce ideas and invest them properly.

5. Psychology is important in the educational process, as it develops thinking and seeks to adjust the learner's behavior appropriately.
6. Future thinking helps to develop planning, perceptions, forecasts and solving problems that may occur.

\section{The study importance}

The study is importance in terms of practicality as follows:

1. The study provides the educational side with a comprehensive survey on the cognitive load theory, which provides the teachers with new and distinctive teaching methods.

2. The educational-learning program is based on the theory of the cognitive load, which contributes to the crystallization of the practical aspect.

3. The study directs the teachers' attention to the selection of the strategies included in the program, and their suitability and ability to develop thinking in general and future thinking in particular.

4. The current study provides a guide for the teacher on how to plan and implement lessons according to the theory of cognitive load, stimulating activities, and their suitability for the topics presented in the course.

\section{Research objective}

This research aims to:

The study makes the educational-educational program based on the theory of cognitive load in the achievement of general psychology for the students of colleges of education and the development of their future thinking known. According to this aim, hypotheses are set:

There are no statistically significant differences at the level of significance (0.05) between the average scores of students of the experimental group and the average scores of the control group students.

There are no statistically significant differences at the level of significance (0.05) between the average scores of the experimental group and the average scores of the control group students. 


\section{Research limits:}

This research is limited to the students of Wasit University, College of Education, First Stage / Department of Educational and Psychological Sciences, Morning Study, for the academic year 2019-2020

Definitions of terms

Effectiveness is "the extent to which the goals of the system coincide with its goals" (Zaitoun, 2004, p. 17).

In terms of procedure, effectiveness is the ability of the educational-learning program according to the theory of the cognitive load to achieve positive results and fulfill the goals of the study in general psychology subject. It is also the development of future thinking among students of the Faculties of Education, the first stage, the Department of Educational and Psychological Sciences, measuring them and treating the results with appropriate statistical means.

The educational learning program: This program is an organized and integrated plan for the study that includes a set of topics designed by the researcher according to the theory of the cognitive load in the collection of general psychology subject for students of colleges of education and the development of their future thinking.

The theory of cognitive load : According to AlFaeli (2015, p. 93), it is "the total mental energy that the learner consumes while processing a learning topic, and this mental energy varies from one subject to another and from one learner to another".

According to the procedural definition of cognitive load theory, it is the theory adopted by the researcher and which the program was based on its principles and philosophical foundations. It is then applied to students (experimental group) to increase their achievement in general psychology and develop their future thinking.

General Psychology: It is "the science that is concerned with studying psychological phenomena with their internal and external, objective aspects integrated into an holistic unit, which is the human's kit and the tool in adapting to the environment" (El-Sayed, 2010, p. 28).

\section{Part Two}

\section{Theoretical background and previous studies}

In this part, the two researchers will review the theoretical background which forms the basis of this research. They also define its general framework, and the relevant sources and literature have proposed.

The first side: the theoretical side

\section{Learning tutorial}

The term program is a relatively modern term compared to the rest of the terms that have ancient historical roots. It is the program that can be defined as "the set of operations that must be performed to reach a specific goal, and the program's role is to organize the relationship between the plan's goals and its projects" ( AlAnani: 2005, 13).

\section{Steps to build educational-learning programs:}

The process of building educational programs related to school curricula needs a specific educational design. There are governing stages for building educational programs:

First: the planning stage:

The educational programs, in all educational stages, reflect the state of society and the extent of scientific progress made at the level of the era. At beginning of the twenty-first century, education specialists agreed on the need for the educational program to meet the progress made in information and communication technology (Al-Husseini, 2004).

Second: the implementation phase:

It is the process of proposing the specifications, conditions and processes necessary to implement the educational program in the schools. Thus, the curriculum is put into actual implementation in the classroom. This means transforming it into a tangible behavioral reality for learners. This process includes two types of operations:

The first: administrative: It is the educational, human, psychological, and material preparation and preparation for implementation. 
Other: educational: The other phrase is to teach the program to learners through teaching strategies (Hamdan, 1988).).

\section{Third: the evaluation phase}

It is the process of subjecting the educational program to the budget and appreciation to find out the weaknesses to amend and fix them. It also aims to show the strengths to improve, develop and preserve them. In addition, the extent of acceptance and willingness of teachers to implement it are shown. This phrase also uncovers its suitability for the educational goals, the level of the learners, their interests and preferences, after defining the goals and the developing means to achieve them (Ali \& Hamad, 2015).

\section{Second: previous studies}

The two researchers conducted a scientific field tour in Iraqi universities and government libraries, and corresponded with some Arab universities and specialized research centers, via the Internet to obtain previous studies that have a direct relationship to the research variables.

According to Abu-Jawde (2004), the program is "the effect of an educational program - learning based on the cognitive load theory of developing critical thinking skills," aimed at measuring critical thinking skills and building an educational program according to the theory of cognitive load - Aboud (2013) states that it is "the effectiveness of the formalism strategy based on the cognitive load theory in the achievement of Chemistry and scientific thinking of the first intermediate students". The study aimed to measure scientific thinking and measure the effectiveness of formalism strategy on academic achievement.
Eisenchlas, \& Trevaskes (2005) state that this program shows "the effectiveness of a training program based on cognitive strategies for learning in developing future thinking and achievement among students of the University of Wisconsin." The study attempted to build a measure of future thinking and a training program based on cognitive strategies. As for the Hartje (2008), it is "developing and evaluating the effectiveness of an educational bag for multiple educational methods in encouraging students to use future thinking. The study built a scale for future thinking and developed and evaluated an educational portfolio for educational means.

\section{Part Three}

Research methodology and procedures

To identify the effect of the educationallearning program on the achievement of general psychology and the development of future thinking, the two researchers used the experimental method to know the effectiveness of the program.

\section{First: Experimental Design}

The experimental design is an artificial position to test the validity of the hypotheses in which the extraneous variables are isolated. Also, the effect of the independent variable on the dependent variable is studied in order to ascertain the validity of a certain information (Melhem, 2000).

Therefore, the two researchers randomly selected the control group with pre and post test, to suit the circumstances of this research as in the following table: Table (1) experimental design in this work

\begin{tabular}{|l|l|l|l|}
\hline group & Pre-test & Independent variable & Post-test \\
\hline Experimental & $\begin{array}{l}\text { Achievement test } \\
\text { and a measure of } \\
\text { future thinking }\end{array}$ & $\begin{array}{l}\text {-learning } \\
\text { educational program }\end{array}$ & $\begin{array}{l}\text { Achievement test and } \\
\text { future thinking scale }\end{array}$ \\
\cline { 1 - 3 } Control & & & \\
\hline
\end{tabular}

Second: Population Research and its Sample

The community of this research consisted of firststage students in the Department of Educational 
and Psychological Sciences in the Faculties of Education for the academic year 2019-2020. The research sample indicates that it is a partial group of the original community of the research, with the characteristics of this society, representing it in relation to the phenomenon subject of the research (Melhem, 2000). The two researchers chose the Department of Educational and Psychological Sciences at the College of Education, Wasit University because of its proximity to the two researchers. (198) male and female students are divided into three groups (A, $\mathrm{B}$, and $\mathrm{C}$ ), where the two researchers selected randomly, including the research sample consisting of two divisions: the experimental group (b) and the control group (a)

Table (2) the number of the students in the two

$$
\text { groups }
$$

\begin{tabular}{|l|l|l|}
\hline No. & Group & Group \\
\hline 65 & B & Experimental \\
\hline 65 & A & Control \\
\hline 130 & Total & \\
\hline
\end{tabular}

Three: quality of the two groups

Before starting the experiment, the two researchers were keen on the statistically equivalence of the two research groups in a number of variables. These variables are believed to affect the safety of the experiment by analyzing the theoretical framework of the dependent variables, and these variables are:

1. The chronological age is calculated in months.

2. The pretest for future thinking.

3. Intelligence

4. Average

5. Sex

The two researchers obtained the information related to chronological age, through a special form prepared and distributed to the students, which includes the disclosure of this information.

Third / Controlling extraneous variables (external safety of experimental design

1. Processes related to maturity

2. Differences in sample selection
3. Statistical regression

4. Measurement tool

Fourth / The Impact of Experimental Procedures:

1. Academic Subject

2. Class Distribution

3. Instructor

4. Department Building

5. Duration of Experience:

The duration of the experiment was uniform and equal for the two research groups, as it began on Sunday $9 / 2 / 2020$ and ended on Thursday, $6 / 25 / 2020$.

Fifth: Experiment Requirements: - Determining behavioral goals: - Teaching plans:

Sixth / two search tools

The following is a detailed explanation of the steps for building the test:

Determining the purpose of the test:

The test aims to measure the achievement of students in the two research samples after teaching them the prescribed classes of General Psychology for the first stage in the departments of educational and psychological sciences.

\section{Determine the test dimensions:}

The research is determined by the six levels of knowledge domain from Bloom's cognitive classification (knowledge, understanding, application, analysis, synthesis, evaluation).

Determine the number of test items:

The two researchers sought the opinions of a number of teachers of the Department of Educational and Psychological Sciences and the opinions of experts after reviewing the behavioral objectives of the content of the prescribed material. Then, it was agreed to limit the test items with (40) (and according to their relative importance) in order to be more representative of the material.

\section{Test validation:}

Test validation means the measuring instrument ability to measure the goals to be tested accurately without affecting the result by other factors, i.e. it measures what should be actually examined (Mansi, 1999). To verify the validity of the test and its ability to achieve the objectives, the 
researcher verified the validity of the test with two indicators:

1. Validity of the virtual test:

It is the estimation of a number of referees about the extent to which the items achieve the feature to be measured. It is the apparent validity reached by a qualified expert in principle for the contents of the test, i.e. looking at the test items in terms of vocabulary and their formulation, clarity, and knowledge (Al-Nabhan, 2004).

2. Validity of the content:

This validity is intended to design a test so that covers all parts of the subject that students studied at a specific stage. It also deals with the objectives of teaching the subject that students should achieve (Al-Hariri: 48,2008), meaning that the validity of the content is achieved through the specification table (test map). Also, the researchers confirmed stability of testing the test items using the equation (Alpha Cronbach), which is suitable for both types of tests (objective and subjective).

\section{Future thinking scale:}

Since this research aims to know the effectiveness of the educational-learning program in developing future thinking among students of the Faculties of Education (the first stage - the Department of Educational and Psychological Sciences), it was necessary to have an appropriate measurement tool to test future thinking. Thus, the researchers built a scale for this purpose. The skills are proposed by Hafez (2015) and also part of the skills suggested by Abu Shukair and Aql (2016).

\section{Description of the future thinking scale:}

The future thinking scale consists of 40 multiple choice question items, representing a mental process that measures the learner's ability to think. There are five options that take grades $(1,2,3,4$, 5) or vice versa according to the direction of the item. Also, sign is placed on choice of the learner. The highest score for the scale is (200) and the lowest score (40) and with the scale the instruction sheet that included how to answer it from choosing only one option.
Psychometric characteristics of the future thinking scale:

\section{First: Outward Honesty:}

The researcher verified the apparent validity of the scale by presenting it to a group of referees in educational and psychological sciences, measurement and evaluation, to evaluate its items and to determine the extent of their suitability to measure the characteristic to be tested. It also tests their suitability for the sample of the research. It language is refined to to become more applicable to the research sample.

\section{Eighth / statistical means}

1. The chi-square equation: This equation was used to find out the equivalence of the two groups in the educational achievement of the parents.

The t-test for two independent samples (t-test) was used to perform equivalence operations between the two groups (experimental and control) and the final scores of the achievement and future thinking tests. The test ( $t$ ) for the two correlated samples calculates the level of growth in the results of the pre- and post-trial group thinking test results .

\section{Part Four}

First / Presentation and interpretation of the result:

The two hypotheses of the research stated that:

There are no statistically significant differences at the level of significance (0.05) between the average scores of the experimental group and the average scores of the control group students.

To verify the validity of the hypothesis, the final achievement test was applied, and the scores of the students of the two research groups (experimental and control) calculated, and treated statistically using the T-test, it was found that the arithmetic mean of the experimental group equals 43,5538 with a standard deviation of $(5,1902)$. However, the arithmetic mean of the control group is equal to 36,7846 with a standard deviation of 4,7483, and after using the T-test for two independent samples, it was found that the 
calculated $T$ value $(6,7692)$ is greater than the tabular $\mathrm{T}$ value of 1.96 at the level of significance (0.05) and the degree of freedom (128).

The second hypothesis is there are no statistically significant differences at the level of significance (0.05) between the average scores of the experimental group students and the average scores of the control group students in the traditional measure of future thinking.

The future thinking scale is applied and, the scores of the students of the two research groups (experimental and control) are calculated and analyzed, statistically to verify the hypothesis. The T-test for two independent samples was used. As a result, the arithmetic mean and standard deviation of the experimental group are 140,9823 with a of 6,2728 respectively while for the control group, they are 134,9538 and 6,0452) respectively. After using the T-test for two independent samples, it was found that the calculated $T$ value $(5,4960)$ is greater than the tabular $\mathrm{T}$ value of (1.96) at the level of significance (0.05) and the degree of freedom (128).

\section{Second / Conclusions:}

In light of the results presented above, the two researchers concluded the following:

1. The educational-learning program stimulates students' abilities to learn to think, and how to benefit from the way they think about life, not just memorizing information.

2.The cognitive load theory and the strategies emanating from it make learning easier, and it is stored in the minds of students by means of schemes and cognitive forms.

Third / Recommendations:

In light of the results and conclusions reached by the researchers recommend the following:

1. The educational programs are recommended to rely on on the cognitive load theory in teaching general psychology for the first stage in colleges of education, for its effectiveness in raising the level of academic achievement and developing their future thinking.
2. The study also recommends diversification in using modern teaching strategies in teaching by university professors, especially the strategies stemming from the cognitive load theory.

\section{Fourth / Proposals:}

The study proposes the followings:

1. Conducting a study similar to this study for other subjects such as Teaching Thinking, Developmental Psychology, Curriculum and Textbook.

2. Conducting a comparative study between the educational program based on the theory of cognitive load, and educational programs based on other theories, to identify the best ones in teaching psychology.

\section{References}

[1] Aboud, S. A. A. (2013). The effectiveness of the strategy based on the theory of formal cognitive load in the collection of material chemistry and scientific thinking among students first grade average. Basic Education College Magazine For Educational and Humanities Sciences(11), 613-633.

[2] Abu-Jawde, S. S. (2004). The Effect of Teaching-Learning Program Based on Cognitive - Load Theory on The Development of Critical Thinking Skills of A Sample of 10 Basic Grade Students. (PhD Unpublished). Amman Arabic University, Amman.

[3] Al-Ahbani, M. A. H. (2017). The Impact of the Educational Model on University Students' Achievement of General Psychology and the Development of Their Lateral Thinking. (Master ). Tikrit University,

[4] Al-Faeli, H. (2015). Systemic Intelligence in the Theory of Cognitive Load . Cairo

[5] The Anglo-Egyptian Library.

[6] Al-Husseini, A.-H. (2004). The development of educational programs and 
the role of scientific research - The mechanism for developing educational programs, a historical overview. Beirut: Lebanese University.

[7] Al-Nabhan, M. M. (2004). Fundamentals of Measurement in the Behavioral Sciences. Amman: Al-Shorouk Publishing House

[8] Al-Zaghoul, I. A.-R. (2012). Principles of Educational Psychology (2 ed.). Al-Ain, UAE: University Book House.

[9] Ali, U. a.-K. B., \& Hamad, Z. B. (2015). The intensity of educational programs and their impact on the performance of primary education teachers. (Master). Shahid Hamma Lakhdar University, Algeria.

[10] El-Sayed, A. H. M. (2010). General Psychology Cairo: Dar Al-Gharib for Printing and Publishing.

[11] Hamdan, M. Z. (1988). The Contemporary Curriculum: Its Elements, Sources and Its Building Processes. Amman,: Modern Education House.

[12] Mansi, M. A.-H. (1999). Statistics and Measurement in Education and Psychology. Alexandria: House of Knowledge University.

[13] Melhem, S. M. (2000). Measurement and Evaluation in Education and Psychology Amman: Dar Al Masirah for Publishing and Distribution.

[14] Zaitoun, K. A.-M. (2004). Teaching Science to Understand a Constructivist Vision. Cairo: The World of Books

[15] Eisenchlas, S. \& Trevaskes, K. (2005). Cognitive learning strategies programmed practices efficacy in Predictive \& hypothetical thinking skills. The University of Wisconsin, Madison, p213, Abstract Dissertation, Pro-Quest.

[16] Hartje, D. (2008). An Examination of The Process of Implementing Futuristic Imagination Programs in Schools. Fordham University, 208 pages, AAT 3210268, Abstract Dissertation, Pro-Quest
[17] Hariri, Rafidah (2008): Educational Assessment, House of Curricula, Amman, Jordan 